\title{
MODEL OF INTEGRATED TRANSPORTATION SYSTEM
}

The article presents the possibilities of an integrated transport system modeling simulating the complexity of regional transportation and its effects. The modeling methods deal with individual behavioral units and proceed through several steps to estimate travel.

Keywords: Modeling, simulation, regional transportation, hybrid model.

\section{Introduction}

The possibilities of the simulations in the transportation area are quite huge. The main objective is usually to develop a set of mutually supporting realistic simulations, models and data bases that employ advanced computational and analytical techniques to create an integrated regional transportation systems analysis environment.

\section{Model concept description}

The modeling methods deal with individual behavioral units and proceed through several steps to estimate travel. The system predicts trips for individual households, residents, freight loads, and vehicles rather than for zonal aggregations of households.

The Household and Commercial Activity Disaggregation Module creates regional synthetic populations from census and other data. Using activity-based methods and other techniques, it produces a travel representation of each household and traveler.

The Intermodal Route Planner involves using a demographically defined travel cost decision model particular to each traveler. Vehicle and mode availability are represented and mode choice decisions are made during route plan generation [1]. The method estimates desired trips not made, induced travel, and peak load spreading. This allows evaluation of different transportation control measures and travel demand measures on trip planning behaviors.

The Travel Microsimulation executes the generated trips on the transportation network to predict the performance of individual vehicles and the transportation system. It attempts to execute every individual's travel itinerary in the region. For example, every passenger vehicle has a driver whose driving logic attempts to execute the plan, accelerates or decelerates the car, or passes as appropriate in traffic on the roadway network. The Travel Microsimulation produces traffic information for the Environmental Models and Simulations to estimate motor vehicle fuel use, emissions, dispersion, transport, air chemistry, meteorology, visibility, and resultant air quality [2]. The emissions model accounts for both moving and stationary vehicles. The regional meteorological model for atmospheric circulation is supplemented by a model for local effects. The dispersion model is used for directly emitted contaminants and handles both local and urban scale problems. The air chemistry model includes dispersion, but is designed to deal with secondary pollutant production on larger scales.

\section{Household and commercial activity disaggregation module}

The Household and Commercial Activity Disaggregation (HCAD) Module contains two submodules, Synthetic Populations and Activity Demand and Travel Behavior.

\subsection{Synthetic Population submodule}

The Synthetic Population submodule creates a regional population imitation whose demographics closely match that of the real population. The imitation households also are

\footnotetext{
* ${ }^{1}$ Frantisek Brumercik, ${ }^{1}$ Michal Lukac, ${ }^{2}$ Zbigniew Krzysiak, ${ }^{3}$ Leszek Krzywonos

${ }^{1}$ Mechanical Engineering Faculty, University of Zilina, Slovakia

${ }^{2}$ University of Life Science in Lublin, Faculty of Production Engineering, Poland

${ }^{3}$ Lublin University of Technology, Faculty of Mechanical Engineering, Poland

E-mail: brumercikf@fstroj.uniza.sk
} 
distributed spatially to approximate the regional population distribution. The synthetic population demographics are provided to the Activity Demand submodule to derive individual and household activities requiring travel. The household locations determine travel origins and destinations [3].

The underlying theme of represented simulation concept is that individual behavior and their interactions, as constrained by the transportation system, generate the transportation system performance. To affect that performance in a transportation system simulation, individual behavior must be modeled. The Synthetic Population submodule begins the process of creating those "individual" models.

Figure 1 shows the agent based population model based on Geographical information Science (GIS) data.

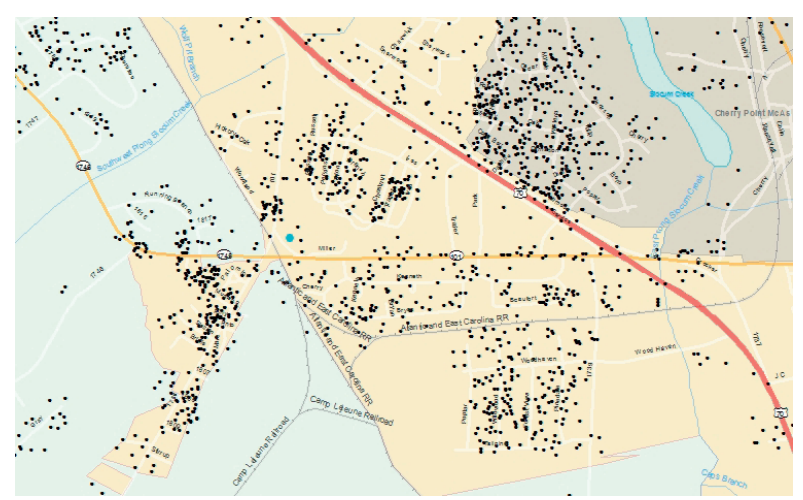

Fig. 1 Agent based population model based on GIS data (Source: [4])

\subsection{Activity Demand and Travel Behavior submodule}

The purpose of the Household and Commercial Activity Disaggregation and Activity Demand submodule is to generate household activities, activity priorities, activity locations, activity times, and mode and travel preferences. The activities and preferences are functions of the household demographics created by the Synthetic Population submodule. The Intermodal Route Planner uses the activities and preferences to determine individual and load trip plans for the region [5 and 6].

Households and businesses have activities that must be, or are desired to be, performed during the day. Many of these activities require the transportation system to move a load (individual or freight) to a certain place at a certain time. Thus, activity demand generates travel demand. These activities and how they are performed depend on the demographics of the household and its individuals, or on the nature of the business. In the presented simulation concept the interest is focused on traveler activities; modeling commercial load activities will be difficult until more data is available on shipping
[7]. Traveler activities are aggregated at a low level into household activities. Household activities then are estimated from probability distributions dependent on the household demographics. These demographics include the ages of the inhabitants, the household family type (single, married couple, married couple with small children, married couple with older children, etc.), the household income, the number of cars on the household and the members of the household who can drive. These demographics are produced by the Synthetic Population submodule.

The main feedback mechanism from traffic behavior Dynamic Traffic Assignment (DTA) to an activity-based model $(\mathrm{ABM})$ is the so-called skim matrices, which are the zone-to-zone (or parcel-to-parcel or location-to-location) travel times informed by the traffic simulation model (Fig. 2).

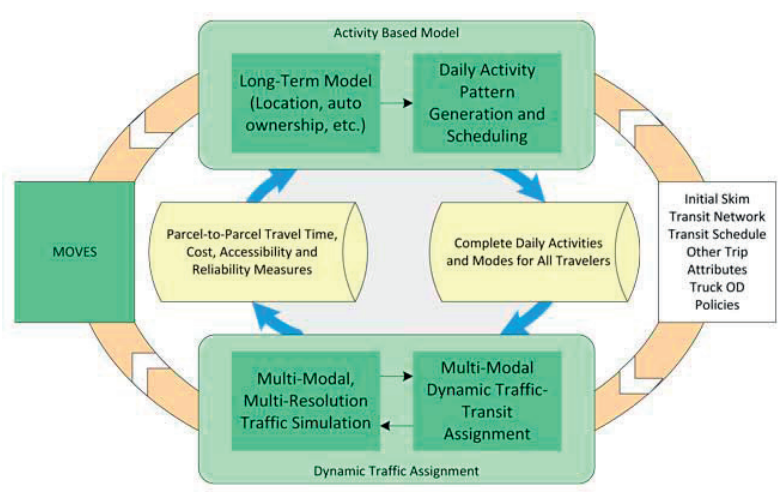

Fig. 2 Feedback mechanism between DTA and ABM (Source: [8])

\section{Intermodal route planner}

The Intermodal Route Planner generates regional individual activity-based travel demand.

A "load" is a traveler or a commodity. A trip plan is a sequence of modes, routes, and planned departure and arrival times at the origin, destination(s), and mode changing facilities projected to move the load to its activity locations. It is assumed that travel demand is derived from a load's desire or need to perform activities. The HCAD provides the Planner with disaggregated activity demand and travel behavior. The Planner assigns activities, modes, and routes to individual loads in the form of trip plans [9]. The individual trip plans are input to the Travel Microsimulation for its analysis. Trip plan selection is related directly to a load's desire to satisfy individual (or in the case of freight, corporate) goals. Goals measure a trip plan's acceptability and depend on the load's socioeconomic attributes and trip purpose. Typical goals include cost, time, and distance minimization and safety and security maximization. The load's objective is to minimize the deviations from these goals. 
Mode and route preferences also are important in the Planner. A preference is the inherent partiality or bias a load has for a particular mode or route. Typical preferences include departure time, origin-destination directedness and congestion avoidance. These preferences reduce the Planner's (activity, mode and route) solution space and offer significant computational savings.

The graphic of an intermodal route planner for East-West Corridor is shown in Fig. 3.

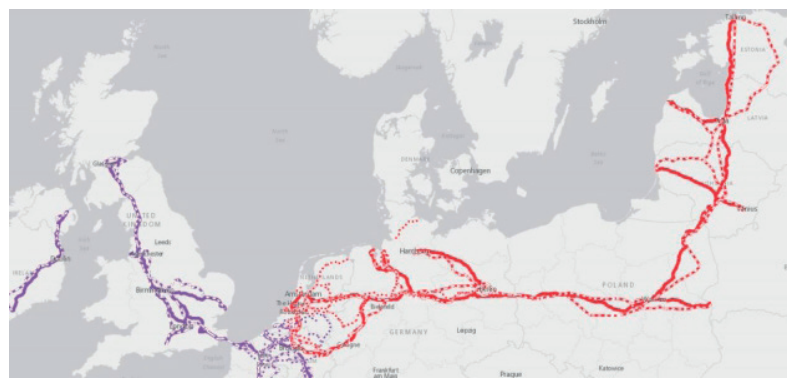

Fig. 3 Graphic of an intermodal route planner for East-West Corridor (Source: [10])

\section{Travel microsimulation}

The Travel Microsimulation module mimics the movement and interactions of travelers throughout a metropolitan region's transportation system. For this discussion, traveler refers both to human travelers as well as freight loads, etc. The Intermodal Route Planner provides a trip plan to each traveler that he then attempts to execute on the transportation network. In the process he interacts with other travelers and the transportation system. The combined traveler interactions produce emergent behaviors such as traffic congestion.

The Travel Microsimulation models many transportation modes including automobiles, trucks, buses, light rail, commuter rail, bicycles, and pedestrians. Thus, the microsimulation includes roadway, transit, rail, bikeway, and pedestrian networks. In the following discussion, the microsimulation is illustrated with roadway transportation examples because of its high use, complexity, and importance to air quality.

The roadway network includes freeways, highways, streets, ramps, turn lanes, grades, and intersections (signalized or non-signalized). In executing their trip plans, vehicle drivers accelerate, decelerate, turn, change lanes, pass, and respond to other vehicles and signs and signals. Drivers exhibit behavior between aggressive and passive. Vehicles have weight and acceleration and deceleration characteristics [11].

Analysis requirements determine the necessary microsimulation detail. Increasing the microsimulation detail increases its behavioral representation of real transportation systems, but it also increases its computational burden. The representation quality is called the model's fidelity. One goal is to find the minimum computational detail necessary to produce the fidelity needed for specific analyses. This minimum computational detail is also called critical complexity. A hybrid technique uses high-fidelity microsimulations for areas where detailed results are needed and low-fidelity, fast-running microsimulations for areas where there is less interest. This hybrid microsimulation requires matching the microsimulations at their boundaries. The flowchart of the classic approach to the travel microsimulation is shown in Fig. 4.

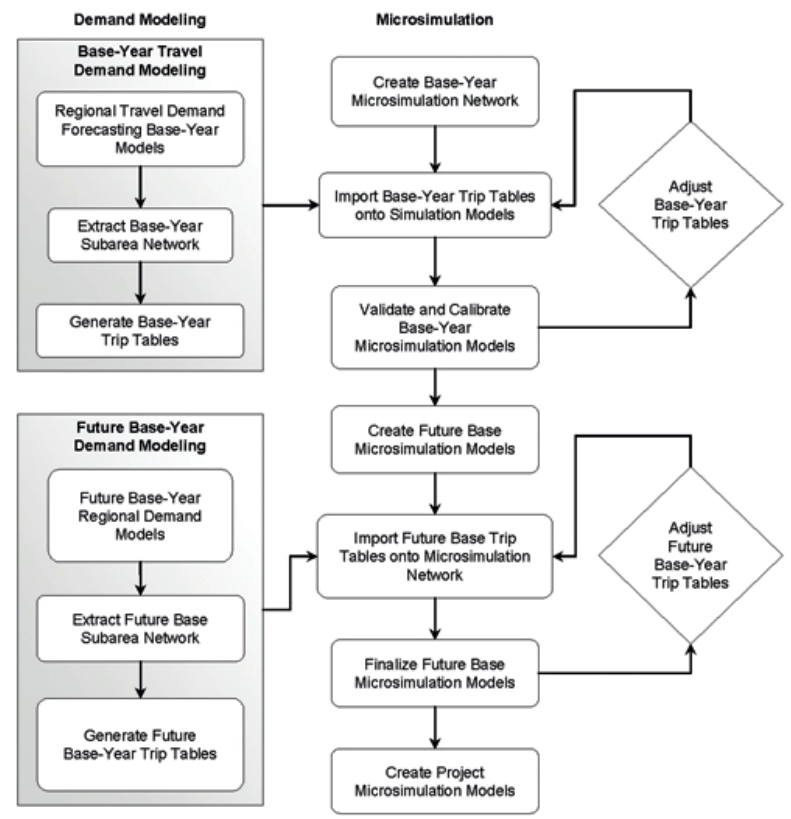

Fig. 4 Flowchart of the classic approach to travel microsimulation (Source: [12])

\section{Environmental models and simulation}

The purpose of the environmental module is to translate traveler behavior into consequent air quality, energy consumption, and carbon dioxide emissions. The environmental module will use information from the planner and the microsimulation and it will support the analyst's toolbox. It also could provide information on fog to the microsimulation.

Transportation systems play a significant role in urban air quality, energy consumption and carbon-dioxide emissions. Recently, it has been found that current systems for estimating emissions of pollutants from transportation devices lead to significant inaccuracies. When these inaccuracies are coupled to air quality models and limited meteorological data, it is difficult to tell whether the most appropriate path is being 
taken to achieve air quality goals. Most existing emission modules use very aggregate representations of traveler behavior and attempt to estimate emissions on typical driving cycles [13]. However, recent data suggests that typical driving cycles produce relatively low emissions with most emissions coming from off-cycle driving, cold-starts, and evaporative emissions. Furthermore, some portions of the off-cycle driving such as climbing steep grades are apt to be correlated with major meteorological features such as downslope winds. These linkages are important, but they are not treated systematically in the current modeling systems [14].

\section{Conclusion}

By applying forefront technologies and methods, the represented integrated transportation model can simulate the dynamic details that contribute to the complexity inherent in today's and tomorrow's transportation issues. The integrated results from the detailed simulations can support transportation planners, engineers and others who must address environmental pollution, energy consumption, traffic congestion, land use planning, traffic safety, intelligent vehicle efficacies and the transportation infrastructure effect on the quality of life, productivity and economy [15 and 16].

\section{Acknowledgement}

This paper presents results of work supported by the Slovak Scientific Grant Agency of the Slovak Republic under the project No. VEGA 1/0077/15.

\section{References}

[1] DROZDZIEL, P., KRZYWONOS, L.: The Estimation of the Reliability of the First Daily Diesel Engine Start-up during its Operation in the Vehicle. Eksploatacja i Niezawodnosc - Maintenance and Reliability, vol. 41, No. 1, 2009, 4-10.

[2] GLOWACZ, A.: Diagnostics of DC and Induction Motors Based on the Analysis of Acoustic Signals. Measurement Science Review, vol. 14, No. 5, 257-262.

[3] KOHAR, R., HRCEK, S., MEDVECKY, S.: Usage of Dynamic Analysis to Determine Force Interactions between Components of Rolling Bearings. Communications - Scientific Letters of the University of Zilina, vol. 14, No. 3, 2012, pp. $62-67$.

[4] http://www.gisagents.org/2012/05/synthetic-population-data-for-us.html

[5] CABAN, J., DROZDZIEL, P., BARTA, D., LISCAK, S.: Vehicle Tire Pressure Monitoring Systems. Diagnostyka, vol. 15, No. 3, 2014, ISSN 1641-6414.

[6] http://ops.fhwa.dot.gov/publications/fhwahop 10005/cs4.htm

[7] KOHAR, R., HRCEK, S.: Dynamic Analysis of a Rolling Bearing Cage with Respect to the Elastic Properties of the Cage for the Axial and Radial Load Cases. Communications - Scientific Letters of the University of Zilina, vol. 16, No. 3A, 2014, 74-81.

[8] http://ops.fhwa.dot.gov/publications/fhwahop13015/sec9.htm

[9] CABAN J., MARCZUK A., SARKAN B., VRABEL J.: Studies on Operational Wear of Glycol-based Brake Fluid. Przemyst Chemiczny, vol. 94, No. 10, 2015, 1802-1806.

[10] http://www.ecorys.nl/english/news/ecorys-develops-intermodal-route-planner-east-west-corridor

[11] BUKOVA, B., BRUMERCIKOVA, E., KONDEK, P., SOJCAK, D.: The Impact of International Entrepreneurship on the Development of Transport. Communications - Scientific Letters of the University of Zilina, vol. 18, No. 2, 2016, 139-142.

[12] http://ops.fhwa.dot.gov/publications/fhwahop10005/cs4.htm

[13] HRCEK, S., KOHAR, R., MEDVECKY, S.: Determination on the Maximum Roller Bearing Load with Regards to Durability thereof using FEM Analysis. Communications - Scientific Letters of the University of Zilina, vol. 14, No. 3, 2012, 55-61.

[14] KOMSTA, H., BRUMERCIKOVA, E., BUKOVA, B.: Applications of NFC Technology in Passenger Rail Transport. Transport Problems, vol. 11, No. 3, 2016, 43-53.

[15] BRUMERCIKOVA, E., BUKOVA, B., KRZYWONOS, L.: NFC Technology in Public Transport. Communications - Scientific Letters of the University of Zilina, vol. 18, No. 2, 2016, 20-25.

[16] BUKOVA, B., BRUMERCIKOVA, E., KOLAROVA, P.: A Study of a Logistics Transport Chain in the Transport of Selected Commodity from Eastern Europe to China. Nase more, vol. 62, No. 4, 2015, 256-263. 